\title{
Expectations for consultations and antibiotics for respiratory tract infection in primary care:
}

\author{
the RTI clinical iceberg
}

\begin{abstract}
\section{Background}

Respiratory tract infection (RTI) is the commonest indication for community antibiotic prescriptions. Prescribing is rising and is influenced by patients' consulting behaviour and beliefs.
\end{abstract}

\section{Aim}

To build up a profile of the 'RTI clinical iceberg' by exploring how the general public manage RTI, visit GPs and why.

\section{Design and setting}

Two-phase qualitative and quantitative study in England

\section{Method}

Qualitative interviews with 17 participants with acute RTI visiting pharmacies in England, and face-to-face questionnaire survey of 1767 adults $\geq 15$ years in households in England during January 2011

\section{Results}

Qualitative interviews: interviewees with RTI visited GPs if they considered their symptoms were prolonged, or severe enough to cause pain, or interfered with daily activities or sleep. Questionnaire: 58\% reported having had an RTI in the previous 6 months, and $19.7 \%(95 \% \mathrm{Cl}$ $=16.8$ to $22.9 \%$ ) of these contacted or visited their GP surgery for this, most commonly because 'the symptoms were severe'; or 'after several days the symptoms hadn 't improved'; $10.3 \%$ of those experiencing an RTI (or $53.1 \%$ of those contacting their GP about it) expected an antibiotic prescription. Responders were more likely to believe antibiotics would be effective for a cough with green rather than clear phlegm. Perceptions of side effects of antibiotics did not influence expectations for antibiotics. Almost all who reported asking for an antibiotic were prescribed one, but $25 \%$ did not finish them.

\section{Conclusion}

One-fifth of those with an RTI contact their GP and most who ask for antibiotics are prescribed them. A better public understanding about the lack of benefit of antibiotics for most RTIs and addressing concerns about illness duration and severity, could reduce GP consultations and antibiotic prescriptions for RTI.

\section{Keywords}

antibiotics; beliefs; family practice; qualitative research; questionnaire; respiratory tract infections.

\section{INTRODUCTION}

There has been a steady rise in antibiotic resistance worldwide. ${ }^{1}$ As resistance is associated with antibiotic use, ${ }^{2,3}$ and reductions in use have been associated with a fall in resistance, ${ }^{4}$ there have been concerted antibiotic stewardship efforts directed at clinicians ${ }^{5}$ and public expectations for antibiotics for respiratory tract infections (RTI). ${ }^{6}$ Total antibiotic dispensing in primary care in England increased by about 7\% between 2007 and 2011. ${ }^{7}$ Recent poster or leaflet campaigns in England, which encouraged the public not to take antibiotics for acute RTI, probably had little effect on antibiotic use. ${ }^{8}$ In contrast, multifaceted interventions are generally more successful, especially if based on behaviour change theory to address with GPs the importance of antibiotic resistance and its relationship to use, and if they also provide tools to facilitate behaviour change in both patients and clinicians. ${ }^{9-13}$

Although the illness iceberg has been described, ${ }^{14}$ GPs may prescribe antibiotics unnecessarily to the majority of patients presenting with RTIs, ${ }^{15}$ moreover patients who are prescribed antibiotics for RTI have a history of high consultation behaviour and re-attendance. ${ }^{16}$ Antibiotic prescribing decisions should take individual patient perspectives into account; and good data on the patients journey through their RTI illness

CAM McNulty, head of primary care unit, Public Health England, and Cardiff University visiting honorary professor, Microbiology Department, Gloucestershire Royal Hospital, Gloucester. T Nichols, statistician, Public Health England, Centre for Infections, Statistics Unit, London. DP French, professor of health psychology, School of Psychological Sciences, University of Manchester, Oxford Road, Manchester. P Joshi, research officer, National Children's Bureau, London. CC Butler, head of institute, Institute of Primary Care and Public Health, School of Medicine, Cardiff University, Cardiff. should help inform GPs' management and the further development and roll-out of multifaceted interventions. 9.17

The aim of this study was to build up a profile of the 'RTI clinical iceberg' by estimating how often members of the general public were affected by an RTI in the past 6 months, how they managed it, how many visited their GP and why, what they expected from this visit and their expectations for antibiotics in a range of clinical scenarios, whether they had been prescribed immediate or delayed antibiotics, and their adherence behaviour.

\section{METHOD}

\section{Overview}

This was a two-phase study; qualitative in depth interviews informed questions which were used in an Ipsos MORI survey conducted in households in England during January $2011 .^{18}$

\section{Qualitative interview study}

A sample of adult members of the public with diverse ethnicity and deprivation were opportunistically recruited in pharmacies in four areas of England. Responders who had recently had an RTI, were asked to participate in a later telephone interview. ${ }^{18}$ The interview structure was based on Leventhal's Common Sense Model ${ }^{19}$ and explored the recent RTI illness episode and

\section{Address for correspondence}

Cliodna McNulty, Public Health England, Primary Care Unit, Microbiology Department, Gloucestershire Royal Hospital, Great Western Road, Gloucester, GL1 3NN.

E-mail: cliodna.mcnultyaphe.gov.uk

Submitted: 22 January 2013; Editor's response: 13 February 2013; final acceptance: 12 March 2013. CBritish Journal of General Practice This is the full-length article (published online $1 \mathrm{Jul}$ 2013) of an abridged version published in print. Cite this article as: $\mathbf{B r} \mathbf{J}$ Gen Pract 2013; DOI: 10.3399/bjgp13X669149 


\section{How this fits in}

To influence the rise in community antibiotic prescribing for acute respiratory tract infection (RTI), which is the commonest indication for antibiotics, we need to understand more about how often and why the general public contact their GP surgery with acute RTI symptoms. This study found that $80 \%$ of the general public with an RTI self-care at home and $60 \%$ take over-the-counter or alternative medicines: $20 \%$ report contacting their GP surgery. The public mainly contact their surgery because they perceive their symptoms are prolonged or severe (disturbing sleep or daily activities); half of responders visiting the surgery expect an antibiotic, but many want reassurance, advice about self-care, a non-antibiotic treatment, or advice about probable illness length. Interventions aimed at reducing antibiotic use should address these patient needs.

what healthcare advice they had sought, if any. ${ }^{18,20}$ All interviews were audiorecorded, transcribed verbatim, and subjected to thematic analysis. ${ }^{18}$ Responder validation was not sought as all participants turned down the offer to be sent the findings for review. Initially, the transcripts were read and codes developed for the themes identified; subsequently the research team read a sample of transcripts, and discussed and agreed the coding. An iterative process was used in which interviews proceeded with the analysis, allowing for exploration of emerging themes during recruitment. After 17 interviews it was agreed that no novel data were being collected. There were no obviously inconsistent findings emerging therefore it was agreed not to look for disconfirming data when developing themes.

\section{Questionnaire survey}

The results of the qualitative interviews were used to inform the survey questions about responders' actions with their most recent RTI illness, and the list of possible actions that responders were then asked to choose from as their answer (Questionnaire available from authors). For the Ipsos MORI questionnaire survey in January 2011, multistage sampling was used to recruit 1767 adults aged $\geq 15$ years from across England for face-to-face interviews in their own home. ${ }^{18}$ Briefly, the interviews form part of Ipsos MORI's weekly 'Capibus' survey; approximately 180 local area authorities are randomly selected in the first stage of sampling. Those selected in Wales and Scotland do not feature in this study. In the second stage of sampling, one output area of between 60 to 100 addresses is randomly selected from each local area authority. Interviewers are given age and sex quotas of responders for each output area. Interviewers go door-to-door inviting the person who answers (provided they are over 15 years oldl to participate. If that person refuses, interviewers can invite another member of the household. Households are visited throughout the week; during the day, evenings, and weekends so that working people can be included. Interviewers do not revisit non-responding households. About one interview is completed for every three or four doors on which they knock.

Responders were asked several different questions about their expectations for antibiotics, and their antibiotic use. First responders were asked if they expected their GP or nurse to prescribe antibiotics if they went to see them with different RTI conditions; secondly they were asked if in the past year they had asked their GP or nurse for antibiotics for themselves or for someone else for any condition and what happened if they asked; we also asked if in the past year they had been prescribed antibiotics for any condition and if they had finished the course as prescribed, or offered a delayed antibiotic prescription. Responders were then asked whether they agreed with a number of statements about antibiotics, whether they expected different RTI symptoms would get better more quickly with antibiotics, and how much of a problem they thought antibiotic side effects were.

Responders were then asked completely different questions on an unrelated Ipsos MORI topic, before being asked whether they had had sore throat, cold, cough, or flu symptoms in the previous 6 months, how the symptoms of their most recent RTI had affected their general health and what actions they took as a result. If they had contacted or visited their GP surgery with their most recent RTI they were asked their reasons and expectations for consulting. The possible answers to these questions that were derived from the interview responders (plus 'other' and 'don't remember') were displayed on a show card.

Percentages were adjusted using weights defined by sex and, within sex, by age, social grade, region and working status to correct for known selection biases. Social grade is the classification originally developed for the National Readership Survey and based on occupation. All results allow for 


\section{Box 1. Why participants reported they did NOT visit their GP surgery}

\section{RTI wasn't affecting everyday life:}

P34: .... although I've been, like, runny nose, sore throat, I haven't really been, sort of, like I didn't want to get out of bed, or, you know, I just took some tablets - some paracetamol - and just got up and got on with things really.

\section{Don't visit GP surgery with minor illness:}

P25: 'No I didn't, no. No, I wouldn't take up their time with something as simple as that.

P34: 'Because the pharmacy are so helpful, I usually tell them what the symptoms are and they'll tell you basically what the doctor would tell you, the only thing the pharmacy can't do is obviously prescribe antibiotics, and because we'd been to the GP 3 weeks prior to that and he'd had a chest infection but that had cleared up I just thought well, I'm not one of these people that likes to be in the doctors surgery all the time, and I will only take them if it is really bad and they need to go to the doctors.

\section{Know the GP won't give any antibiotics:}

P35: 'because I knew, um, the GP couldn't give me anything, any that I couldn't buy to make myself feel better. I knew they wouldn't give me antibiotics.

\section{Box 2. Why participants reported they visited their GP surgery}

\section{Symptoms were interfering with sleep:}

P39: Hard to breathe, hard to sleep, pains in my stomach through coughing and the chest. I'd just had enough / couldn't cope anymore.

Interviewer: 'Okay was it affecting your day-to-day life?

P39: 'It was yeah, because I was, I just wasn't able to sleep at nights.'

\section{Reassurance that illness didn't require further treatment:}

P26: 'Erm because in previous times when it hasn't cleared up in a few days it usually means she has got an ear infection or something, so I wanted to make sure really.

P35: It's peace of mind really. They do more of an examination like listening to the chest and, you know, examining them more.

\section{Symptoms persistent}

P13: 'Yeah, it was probably Sunday and I probably didn't go on the Sunday because I was just staying in because I wasn't very well over the weekend. So, it's probably in the start of the week, when I wanted my system to start feeling better [that I went to the GP].

\section{Severity of illness affecting day to day activities:}

P33: Yeah I did [visit GP], I had been taking over-the-counter tablets, I started them at the beginning when I had my cold but I just didn't feel that they were doing anything at all, so I felt as if I needed something stronger. So it makes me feel so rotten that's why I felt I had to go to the doctors.

\section{Family or peer pressure to visit GP:}

P6: 'Because it didn't stop me going out with the dog or anything like that, it was only when my breath became inhibited somewhat that I thought, and the nagging of others, that I should really take some medical advice.

\section{Box 3. Why participants expected antibiotics}

\section{Symptoms or illness severe enough to warrant antibiotics:}

P39: You just wait and see and try and ride it out yourself. Until or if it affects you too much ... This time because I'm in a different kettle of fish now because I'm asthmatic it's hit me more than any other flu or cold that l've ever had. Simply because I'm asthmatic and the only thing that would deal with me then was antibiotics, which I'm on now, I'm only on my third day and I have felt improvements.

P34: I can look at my children and I know when they're seriously ill, and that's when you know as a mum you can look and you know in yourself, obviously when you can't move, you can't ... everything, then everything hurts, you shiver and you shake. There's just so many different symptoms and it's if you've got the whole lot in one go and you don't get any better like within 2 days nothing helps, then I'd say you need antibiotics, if nothing else does the job. using Stata (version 11.2). Significance tests for differences in percentages were a variation of the Pearson $\chi^{2}$ test. $^{18}$ Significance tests include no correction for the number of possible comparisons that could have been made.

\section{RESULTS}

\section{Qualitative interview study}

Seventeen participants who had recently had RTI or flu symptoms (10 female, 16 white, one south Asian) were interviewed between 3 and 8 days after their pharmacy visit. ${ }^{17}$ The eight participants who had visited a pharmacy and not their GP surgery did not report that their illness was affecting their day to day life, (Box 1) and did not describe pain as a symptom. The nine participants who had also visited their GP had two things in common: their symptoms affected day-to-day life, sleep, or activities, and they described symptoms that included pain (Box 2). Several participants mentioned that they had visited their GP because they wanted reassurance, or were prompted to go by family or friends. Several participants reported that they would not expect antibiotics for a cough or cold, but would if symptoms were prolonged or severe, or if they had an underlying illness such as asthma (Box 3).

\section{Questionnaire survey}

Of all adults surveyed, $58 \%(95 \% \mathrm{Cl}=54.8$ to $61.3 \%$ ) reported RTI symptoms in the past 6 months (Figure 1); this includes sore throat in $25 \%$, cold $37 \%$, cough $26 \%$, or flu symptoms $14 \%$.

\section{Actions with their most recent RTI symptoms}

Of the 1000 adults with recent $R T$ T symptoms, one-fifth reported visiting or contacting their GP surgery because of it $19.7 \%, 95 \%$ $\mathrm{Cl}=16.8$ to $22.9 \%$ ), $60 \%$ reported taking over-the-counter medicines or alternative treatments to relieve their symptoms and $37 \%$ took extra rest. No responders with RTI in the past 6 months reported visiting a NHS walk-in centre and only $1.4 \%$ reported using NHS Direct; $5.7 \%$ reported asking for advice at a pharmacy, and $0.4 \%$ selfmedicated with left-over antibiotics.

\section{Why survey participants contacted their} GP surgery about their most recent RTI Of the 200 adults who had contacted their GP surgery for their recent RTI, $51 \%$ said they did so because their symptoms were severe, $47 \%$ because symptoms had not improved after several days, and $9 \%$ reported that they usually contacted the GP the clustering of the sample within primary sampling units. Initial data processing was carried out by Ipsos MORI, with further data management and all analyses performed 


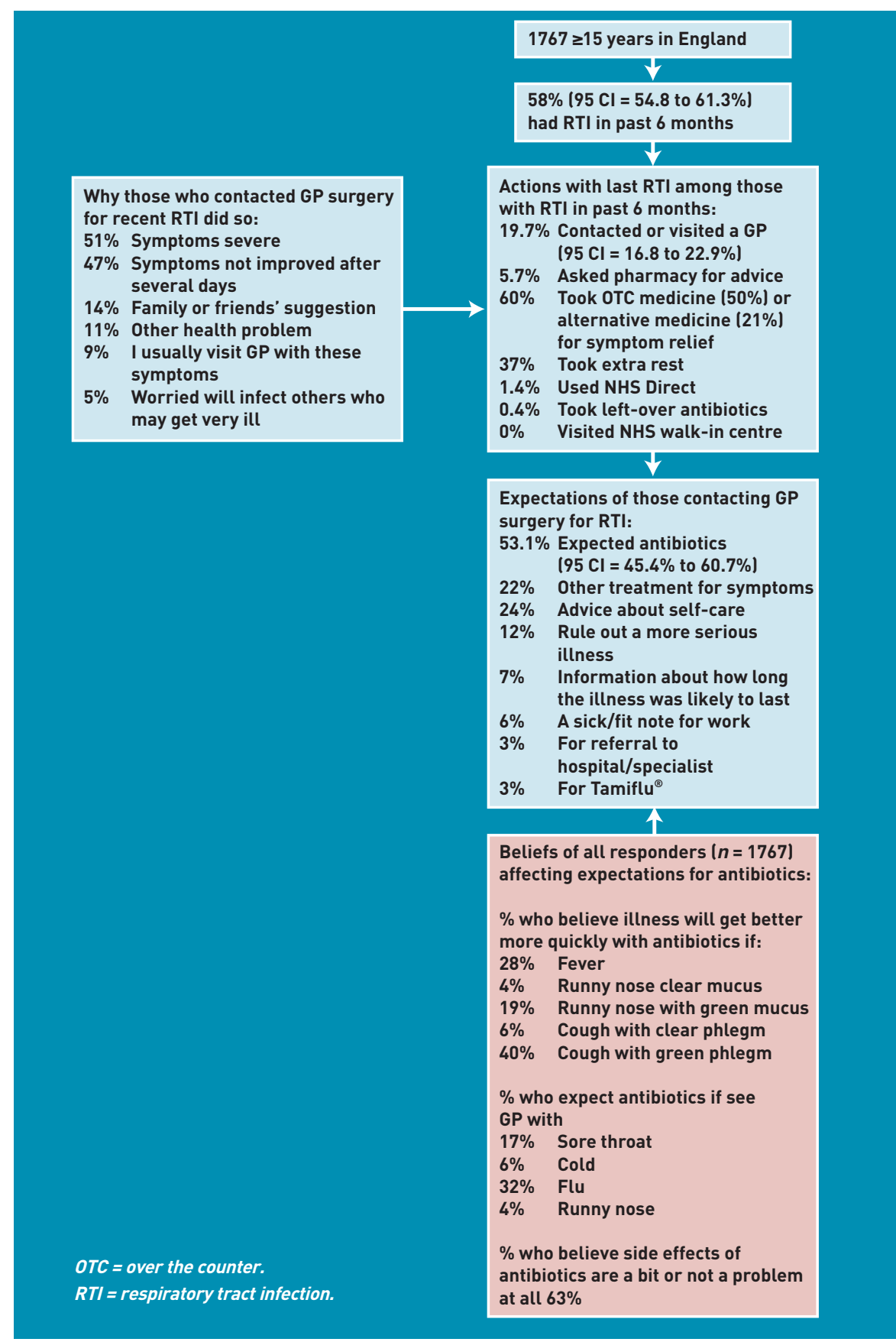

Figure 1. The RTI patient journey: actions of responders with respiratory tract infection in the past 6 months, why they visited the GP and expectations of this visit, and beliefs about antibiotics of all participants that may influence these expectations. with these symptoms. Of these 200 adults who reported contacting their surgery $53.1 \%$ had expected an antibiotic prescription 10.3\% of those with RTI symptoms, Figure 2); $24 \%$ had expected advice about selfcare and $7 \%$ about illness duration, 22\% expected some non-antibiotic treatment for their symptoms, 12\% expected reassurance that the illness was not severe, and 6\% a sick/fit note for work. Of those with an RT in the past 6 months, females of social grade $C 2, D$, or $E$, and men of social grade $\mathrm{D}$ or $\mathrm{E}$ were more likely to have contacted their GP surgery (females: $A B=19 \%$,
$\mathrm{C} 1=18 \%, \quad C 2=31 \%, \quad D E=26 \%, \quad P=0.03$; men: $A B=15 \%, \quad C 1=14 \%, \quad C 2=15 \%$, $\mathrm{DE}=23 \%, P=0.11 \mathrm{l}$. There were no notable differences by age or region.

Survey responders who reported their recent RTI illness had severely affected their health, were more likely to have contacted their GP surgery (50\%), compared to those moderately affected (21\%), mildly affected (7\%), and those not affected at all (12\%), $P<0.001)$. Females were significantly more likely to report being severely affected by their recent RTI compared to men (20\% versus $13 \%$ ), and men of social grade D or E were more likely to report being severely affected than men of social grade $A$ or $B$ (20\% versus $7 \%$ ). Surprisingly age had no effect on RTI severity $16 \%$ of those aged $\geq 65$ years reported being severely affected versus $12 \%$ of those aged $15-24$ years).

\section{Why survey participants expected antibiotics for their most recent RTI}

Of all 1767 adults surveyed, 24\% believed that antibiotics work on most coughs and colds, and $38 \%$ reported believing that antibiotics can kill viruses. Thirty-two per cent of all 1767 responders would expect their GP to prescribe an antibiotic if they went to see them with flu symptoms, 17\% for a sore throat, $13 \%$ for a cough, $6 \%$ for a cold, and $4 \%$ for a runny nose. Survey responders with $\mathrm{RTI}$ in the past 6 months were more likely to have contacted their surgery about their recent RTI if they said they would expect their GP to prescribe an antibiotic for an RTI (27\% versus 14\%), or if they believed that any type of phlegm cough or any type of runny nose would get better more quickly with antibiotics (23\% versus $15 \%$ ). More people believed antibiotics would shorten the duration of illness if phlegm or mucus was coloured green than if coloured yellow or colourless; $40 \%$ of adults believed antibiotics would shorten the duration of a cough with green phlegm, $18 \%$ for cough with yellow phlegm, and $6 \%$ for cough with clear phlegm; 19\% thought a runny nose with green mucus would get better more quickly with antibiotics compared to $4 \%$ who thought a runny nose with clear mucus would benefit.

\section{Effect of side effects of antibiotics on expectations and use}

Of all adults surveyed, $63 \%$ answered that antibiotic side effects were not or only a bit of a problem, $21 \%$ a moderate problem, and $5 \%$ answered they were a major problem. Of those with RTI symptoms in the past 6 months, similar proportions consulted about their RTI whether they believed the 


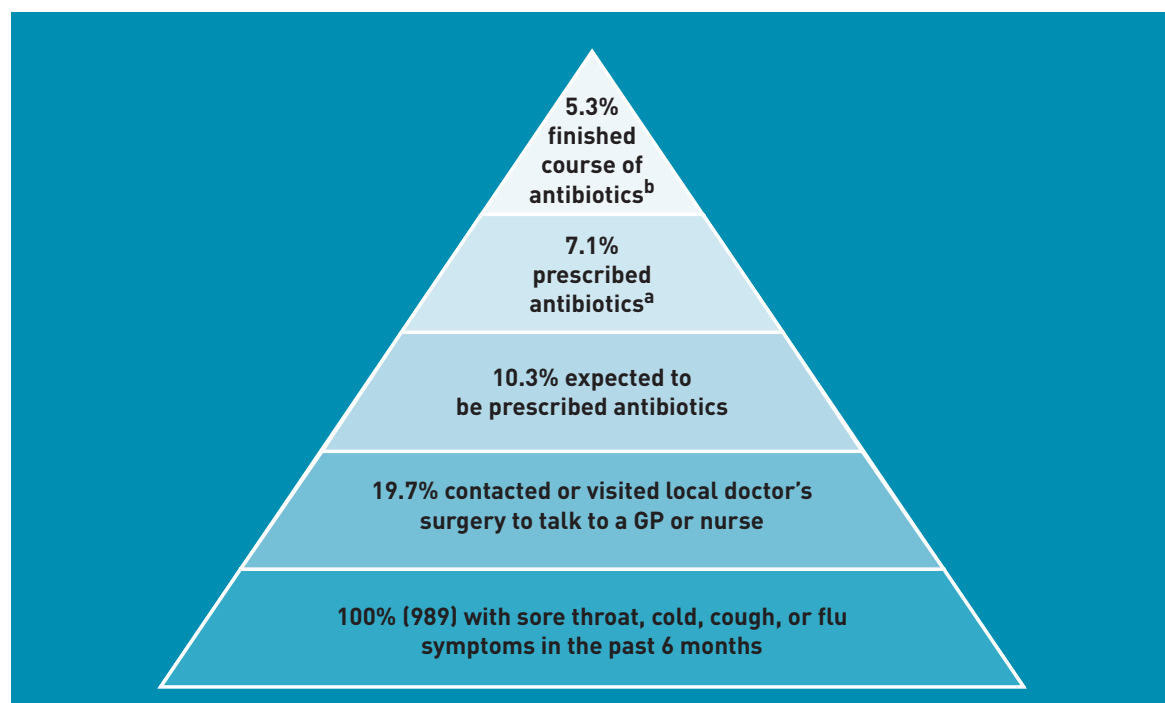

a This figure assumes that those known to have expected to be prescribed antibiotics on this occasion (previous bar) and who responded 'yes' to 'Have you yourself been prescribed any kind of antibiotic in the past year?' were prescribed an antibiotic on this occasion.

${ }^{b} T$ his further assumes that those who we believe were prescribed an antibiotic (see previous footnotel and responded 'I finished the antibiotics/there were none left over' to the question about any kind of antibiotic in the past year, finished a course of antibiotic on this occasion.

Figure 2. The 'clinical iceberg' in RTI. side effects of antibiotics were a major problem $(20 \%)$, or not, or only a bit of a problem (20\%).

\section{Asking for antibiotics for any condition, prescribing and use}

Of the 452 (26\%) responders who reported asking their GP or nurse for antibiotics in the past year, only $3.5 \%$ were refused them, $74 \%$ were prescribed antibiotics after some discussion and $23 \%$ without any discussion about their illness. Of all responders, 14.2\% $(95 \% \mathrm{Cl}=12.1$ to $16.5 \%)$ were offered a delayed antibiotic prescription in the past year (to be cashed in at the pharmacy or collected from the surgery only if they felt no better, or felt worse after several days). Of those $14.2 \%$ of all responders offered a delayed prescription, $63 \%$ collected the antibiotic; and of these $96 \%$ took at least some of the antibiotic. Of the $32.5 \%$ of all responders prescribed antibiotics in the past year: $25 \%$ did not finish them; $11 \%$ did not finish them and kept some; and 5.8\% indicated that they kept their leftovers for possible future use.

\section{DISCUSSION}

\section{Summary}

An RTI clinical iceberg (Figure 2) illustrating that a fifth of adults in England reporting having had an RTI in the previous 6 months went on to contact or visit their GP surgery as a result, $10.3 \%$ of these expected to be prescribed an antibiotic, $7.1 \%$ were prescribed an antibiotic and 5.3\% finish an antibiotic as prescribed. Both the qualitative interviews and survey indicated that participants' appraisal of symptoms was the main influence on whether they sought help from their GP surgery for an RTI. Those who had considered that symptoms were severe or had lasted longer than expected were more likely to seek help. Females of social grade $C 2, D$, or $E$ and men of social grade D or E were more likely to seek help from their GP surgery. There is frequent pressure on GPs to prescribe antibiotics, as half of patients who present to them with an $\mathrm{RTI}$ report expecting antibiotics.

Beliefs about the effectiveness of antibiotics for RTIs were associated with this help-seeking behaviour. Participants who reported expecting their GP to prescribe antibiotics for an RTI were about twice as likely to contact their GP surgery with RTI, but concern about side effects of antibiotics was not associated with their expectations for antibiotics. Almost all responders who reported asking for an antibiotic were prescribed one. One-quarter did not finish their recent antibiotic course, and few reported self-medicating with antibiotics for their recent RTI.

\section{Strengths and limitations}

The face-to-face questionnaire survey was based on a large sample from the general population lone of the few studies to include those not seeking help from clinicians), and the survey instrument was informed by in depth qualitative interviews.

The interview participants were recruited opportunistically in the pharmacy, and this may have lead to recruitment bias. However, the aim of qualitative research is to identify categories of information that are important to the responders themselves, rather than quantifying responses to questions prespecified by researchers from a statistically representative sample. The survey was retrospective so, participants may have forgotten about their antibiotic use or recent RTI, and those with more severe illness may have been more likely to recall details. It was not possible to differentiate between those who reported having upper RTI symptoms from those who may have had a more severe lower RTI, although it is unlikely that any patients in the qualitative part of the study had lower RTI, as they were all interviewed at least 5 days after their visit to the pharmacy, and had mostly recovered from their recent respiratory illness at the time of interview. Some questions may not have been understood 


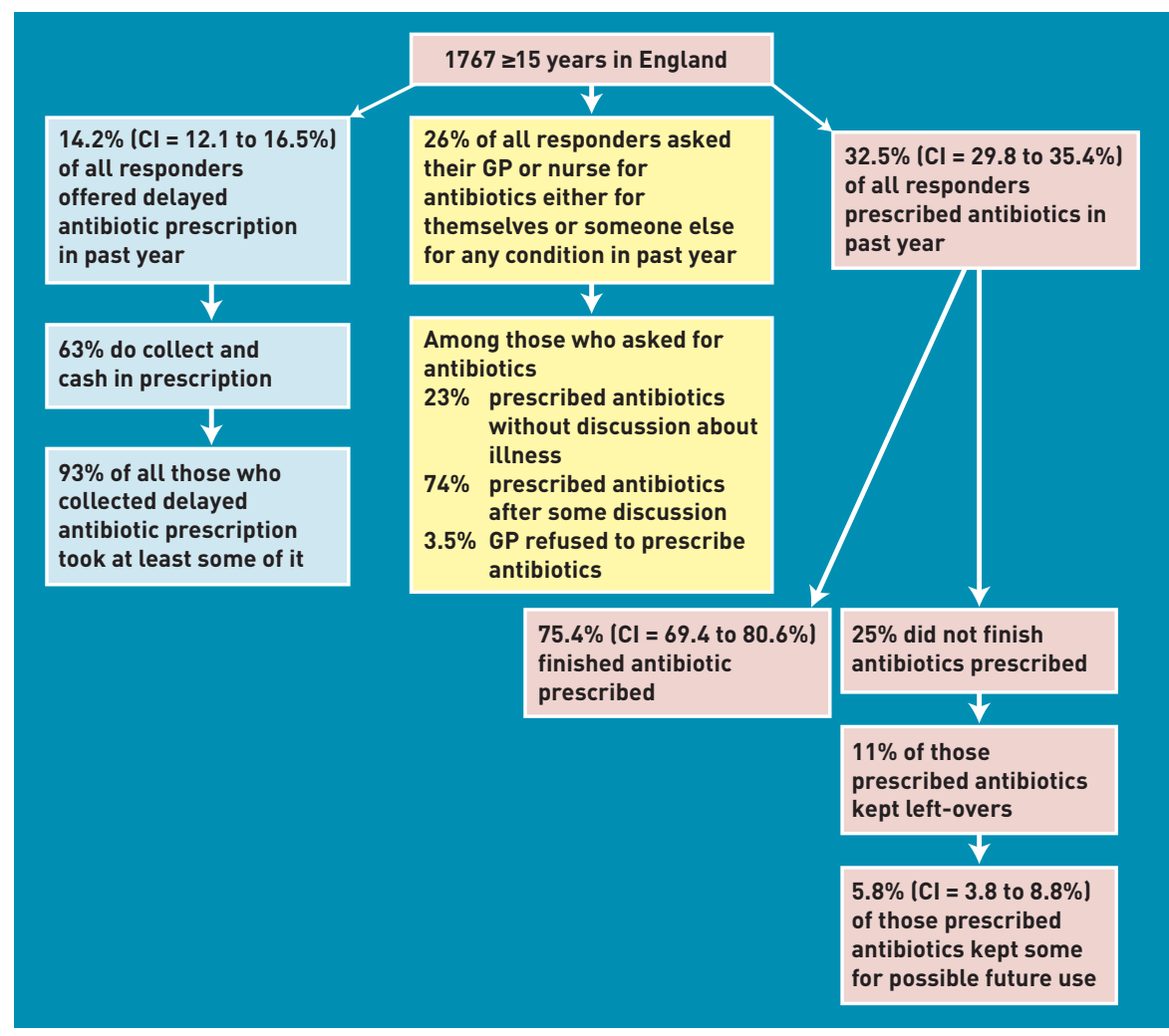

Figure 3. The patient antibiotic story. Reported actions of all 1767 responders in the past year. in the way they were intended, but feedback from interviewers doesn't indicate this. Participants were asked about contact with the GP surgery and prescriptions from a doctor or nurse, but were not asked to differentiate between whom they saw. Thus it was not possible to provide an indication of how many antibiotic prescriptions were issued by different categories of health professional. The $10.3 \%$ of responders who reported having had an RTI in the past 6 months who said they had expected an antibiotic from their GP were not asked whether they actually received one. Thus, the RTI clinical iceberg (Figure 2) assumes that those who expected to be prescribed antibiotics for their recent RTI and who responded 'yes' to 'Have you yourself been prescribed any kind of antibiotic in the past year?' were prescribed an antibiotic on this occasion. The $7.1 \%$ prescribed an antibiotic in the 'RTI iceberg' does not include people prescribed antibiotics who did not expect them; so could possibly be an underestimate.

\section{Comparison with existing literature}

Coenen et al, found that GPs were significantly more likely to prescribe antibiotics for patients consulting with an acute cough if they perceived the patients expected antibiotic treatment. ${ }^{21}$ This study's data supports this, as almost all the participants who asked their GP for an antibiotic were prescribed one, and onequarter of these reported there was no discussion about whether or not to prescribe an antibiotic in their consultation. Delayed antibiotic prescribing may help to reduce this expectation and offer a compromise for both patients and GPs. ${ }^{22}$ These data indicate that this option is commonly used by GPs, as $14 \%$ of participants reported being offered a delayed antibiotic during the previous year.

In a pan-European primary care study, adults with acute cough and/or lower RTI and discoloured sputum were prescribed antibiotics more often. ${ }^{23}$ The current study shows that the public consider that a cough with coloured sputum is more likely to benefit from antibiotic treatment. However, evidence does not show clinically important increased benefit. ${ }^{24}$ Antibioticuse data across Europe shows that the Northern European countries have lower community use of antibiotics than England, ${ }^{25,26}$ suggesting that there may be an opportunity to reduce English patients expectations for antibiotics.

Hannay was the first to describe what he called the illness iceberg in general practice $;^{14}$ he found that $26 \%$ of a GP surgery population had medical symptoms that to them were serious, but for which they did not seek medical advice, the commonest being RTI symptoms. In contrast, $11 \%$ had symptoms that they did not think were serious but for which they visited a GP. ${ }^{14}$ Hannay's iceberg of significant illness symptoms in the community was therefore more than twice the size of so-called trivial complaints. This emphasises the importance of wellinformed shared decision making between patient and GP, about not only their current illness including realistic expectations about time to recovery, ${ }^{27}$ but also about signs and symptoms that should be used to prompt contact with their GP surgery in the future. This current survey showed that the public did indeed contact their GP for advice about self-care, reassurance, and illness duration. Sharing information about the usual illness course with patients or carers encourages self-care.10,13 Van Driel et al found that patients with acute sore throat reported visiting their GP because they expected pain relief, information on illness duration and cause. ${ }^{25}$ Interactive leaflets to share with patients within the consultation have been developed to address such patient concerns, ${ }^{13,17}$ and may facilitate communication in the consultation. Indeed, this may go some way to allay the anxiety 


\section{Funding}

This study was funded by the Health Protection Agency. The Lloyds pharmacy group commented on interviewee information leaflets and pharmacy poster, and on the suitability of selected pharmacy in terms of layout and staffing for the study, but otherwise had no influence on the study design or interviewee selection.

\section{Ethical approval}

The Ipsos MORI survey and interviews were undertaken outside the NHS setting and therefore did not require NHS ethical approval. However, a university Ethics Review Board approved the qualitative aspect of the research. Consent for the Ipsos MORI survey was by verbal agreement to participate at the time of interview.

\section{Provenance}

Freely submitted; externally peer reviewed.

\section{Competing interests}

The authors have declared no competing interests.

\section{Acknowledgements}

We thank Angela Hogan for her help with questionnaire development, Lou Atkinson, Katie Newby, Louise Wallace and Nicholas Russell at Coventry University for their advice and help with the qualitative work; Graham Tanner the patient representative; Andrew Gibb at Lloyds head office and the community pharmacists who allowed patient recruitment; the patients who took part in the interviews; the staff at Ipsos MORI and the public who answered the questionnaire; Mike Sharland, Sally Wellsteed, Christine Robert, and other staff at the $\mathrm{DH}$ who gave advice about questionnaire format.

\section{Discuss this article}

Contribute and read comments about this article on the Discussion Forum:

\section{http://www.rcgp.org.uk/bjgp-discuss}

of patients described by Morrell et al who consult; in their prospective study of females registered with a London general practice, anxiety was significantly associated with the frequency of symptom recording in their health diaries, and with the frequency with which females consulted their GP. ${ }^{28}$ GPs in five European countries mentioned patient demand for antibiotics as a driver for prescribing, and supported patient directed educational materials and public campaigns to reduce demand. ${ }^{29}$

Antibiotic compliance in acute cough, recorded prospectively in patients from Cardiff and Southampton, was much lower $(54 \% \text { and } 58 \%)^{30}$ than the $75 \%$ of participants in this current study who reported finishing their antibiotic course. In contrast, an English telephone survey found that $90 \%$ of responders reported finishing their last course; ${ }^{31}$ retrospective surveys may not be as reliable as the prospective study. In the study 14\% reported being offered a delayed antibiotic, this is higher than the 3\% reported from Cardiff GP surgeries, but lower than the 33\% reported in Southampton GP surgeries. ${ }^{30}$

\section{Implications for research and practice}

As $97 \%$ of patients were prescribed an antibiotic when they asked for one, GPs should consider more often discussing the pros and cons of prescribing antibiotics for RTIs when patients ask for them, and come to a shared decision about the need for antibiotics, balancing the lack of evidence for meaningful benefit from antibiotic treatment for RTI, with patient needs for reassurance and advice. As many patients who contact their GP surgery expect advice and reassurance rather than antibiotics, there is an opportunity for GP practices to give more advice about how patients may relieve symptoms; illness severity and illness length and to address patients' concerns and understanding about the lack of benefit of antibiotics for most RTIs. Particular attention should be given to patients who hold an 'over-optimistic' view of the effect of antibiotic treatment on their RTI symptoms and those who have a history of consulting with RTI; in this current study these were females of social grade C2, D, or $E$, and men of social grade $D$ or $E$, who were more likely to consult their GP surgery with RTI. GPs could also make greater use of one or more of the different variations of delayed prescribing. Addressing the undue emphasis patients put on discoloured sputum and nasal discharge may further help achieve shared antibiotic evidence based prescribing decisions. As 25\% of participants prescribed an antibiotic in the past year reported not finishing the course, clinicians should explain the importance of taking the antibiotic at the correct dose and time interval in the context of likely bacterial infections to attain adequate concentrations for bacterial inhibition or killing and for minimising the emergence of antibiotic resistance; however, it should also be recognised that many antibiotic courses are prescribed in the context of non-bacterial infections. Antibiotic prescribing in RTI is a complex matter that involves balancing the individual needs of the patient with the needs of society to minimise antibiotic resistance in the future. Improving the quality of antibiotic prescribing decisions based on an understanding of the 'RTI clinical iceberg' may help to prolong the useful life of the 'staple' antibiotics used in everyday general practice. 


\section{REFERENCES}

1. World Health Organization. The evolving threat of antimicrobial resistance: options for action. Geneva: WHO, 2012. http://whqlibdoc.who.int/ publications/2012/9789241503181_eng.pdf (accessed 21 May 2013)

2. Costelloe C, Metcalfe C, Lovering A, et al. Effect of antibiotic prescribing in primary care on antimicrobial resistance in individual patients: systematic review and meta-analysis. BMJ 2010; 340: c2096.

3. Malhotra-Kumar S, Lammens C, Coenen S, et al. Effect of azithromycin and clarithromycin therapy on pharyngeal carriage of macrolide-resistant streptococci in healthy volunteers: a randomized, double-blind, placebocontrolled study. Lancet 2007; 369(9560): 482-490.

4. Butler CC, Dunstan F, Heginbothom M, et al. Containing antibiotic resistance: decreased antibiotic-resistant coliform urinary tract infections with reduction in antibiotic prescribing by general practices. Br J Gen Pract 2007; 57(543): 785-792.

5. European Antibiotic Awareness Day. A European health initiative. http://ecdc. europa.eu/en/EAAD/Pages/Home.aspx/ laccessed 21 May 2013).

6. Department of Health. Support European Antibiotic Awareness Day. London: DoH, 2011. http://uww.dh.gov.uk/health/2011/09/eaad/ laccessed 21 May 2013).

7. NHS Prescription Services. Antibiotics national charts 2011. http://uww.nhsbsa. nhs.uk/PrescriptionServices/Documents/PPDPrescribingAnalysisCharts/ Antibiotics_National_June_2012.pdf laccessed 21 May 2013).

8. McNulty CAM, Nichols T, Boyle $P$, et al. The English antibiotic awareness campaigns: did they change the public's knowledge of and attitudes to antibiotic use? J Antimicrob Chemother 2010; 65(7): 1526-1533.

9. Butler CC, Simpson SA, Dunstan F, et al. Effectiveness of multifaceted educational programme to reduce antibiotic dispensing in primary care: practice based randomised controlled trial. BMJ 2012; 344: d8173.

10. Cals JW, Butler CC, Hopstaken RM, et al. Effect of point of care testing for $\mathrm{C}$ reactive protein and training in communication skills on antibiotic use in lower respiratory tract infections: cluster randomised trial. BMJ 2009; 338: b1374.

11. Ranji SR, Steinman MA, Shojania KG, Gonzales R. Interventions to reduce unnecessary antibiotic prescribing: a systematic review and quantitative analysis. Med Care 2008; 46(8): 847-862.

12. Ostini R, Hegney D, Jackson C, et al. Systematic review of interventions to improve prescribing. Ann Pharmacother 2009; 43(3): 502-513.

13. Francis NA, Butler CC, Hood K, et al. Effect of using an interactive booklet about childhood respiratory tract infections in primary care consultations on reconsulting and antibiotic prescribing: a cluster randomised controlled trial. BMJ 2009; 339: b2885.

14. Hannay DR. The symptom iceberg: a study of community health. London: Routledge and Kegan Paul, 1979.

15. Butler CC, Hood K, Verheij T, et al. Variation in antibiotic prescribing and its impact on recovery in patients with acute cough in primary care: prospective study in 13 countries. BMJ 2009; 338: b2242
16. Williamson I, Benge S, Mullee M, Little P. Consultations for middle ear disease, antibiotic prescribing and risk factors for reattendance. A case-linked cohort study. Br J Gen Pract 2006; 56(524): 170-175.

17. Royal College of General Practitioners, Health Protection Agency and members of Antimicrobial Stewardship in Primary Care Group. TARGET antibiotics toolkit. London: RCGP, 2012. www.RCGP.org.uk/TARGETantibiotics/ laccessed 21 May 2013).

18. McNulty C, Joshi P, Butler CC, et al. Have the public's expectations for antibiotics for acute uncomplicated respiratory tract infections changed since the H1N1 influenza pandemic? A qualitative interview and quantitative questionnaire study. BMJ Open 2012; 2(2): e000674.

19. Leventhal H, Benyamini Y, Shafer $\mathrm{C}$. Lay beliefs about health and illness. In: Ayers S, Baum A, McManus C, et al leds.). Handbook of psychology, health and medicine, 2nd edn. Cambridge: Cambridge University Press, 2007: 124-128.

20. Hawkings NJ, Wood F, Butler CC. Public attitudes towards bacterial resistance: a qualitative study. J Antimicrob Chemother 2007; 59(6): 1155-1160.

21. Coenen S, Michiels B, Renard D, et al. Antibiotic prescribing for acute cough: the effect of perceived patient demand. Br J Gen Pract 2006; 56(524): 183-190.

22. Little P. Delayed prescribing of antibiotics for upper respiratory tract infection. BMJ 2005; 331(7512): 301-302.

23. Butler CC, Kelly MJ, Hood K, et al. Antibiotic prescribing for discoloured sputum in acute cough/lower respiratory tract infection. Eur Respir J 2011; 38(1): 119-125.

24. Little P, Stuart B, Moore M, et al. Amoxicillin for acute lower-respiratory tract infection in primary care when pneumonia is not suspected: a 12-country, randomised, placebo-controlled trial. Lancet Infect Dis 2013; 13(2): 123-129.

25. van Driel ML, De Sutter A, Deveugele M, et al. Are sore throat patients who hope for antibiotics actually asking for pain relief? Ann Fam Med 2006; 4(6): 494-499.

26. Ferech M, Coenen S, Malhotra-Kumar S, et al. European Surveillance of Antimicrobial Consumption (ESAC): outpatient antibiotic use in Europe. $J$ Antimicrob Chemother 2006; 58(2): 401-407.

27. Ebell MH, Lundgren J, Youngpairoj S. How long does a cough last? Comparing patients' expectations with data from a systematic review of the literature. Ann Fam Med 2013; 11(1): 5-13

28. Morrell DC, Wale CJ. Symptoms perceived and recorded by patients. J R Coll Gen Pract 1976; 26(167): 398-403.

29. Tonkin-Crine S, Yardley L, Coenen S, et al. GPs views in five European countries of interventions to promote prudent antibiotic use. Br J Gen Pract 2011; DOI: 10.3399/bjgp11X572445

30. Francis NA, Gillespie D, Nuttall J, et al; GRACE Project Group. Antibiotics for acute cough: an international observational study of patient adherence in primary care. Br J Gen Pract 2012; DOI: 10.3399/bjgp12X649124.

31. Pechere JC. Patients' interviews and misuse of antibiotics. Clin Infect Dis 2001; 33 Suppl 3: s170-173. 